HEPATITIS

\title{
Tumour necrosis factor related apoptosis inducing ligand (TRAIL) induces hepatic steatosis in viral hepatitis and after alcohol intake
}

\author{
B Mundt, T Wirth, L Zender, M Waltemathe, C Trautwein, M P Manns, F Kühnel, S Kubicka
}

Gut 2005;54:1590-1596. doi: 10.1136/gut.2004.056929

Background and aims: Tumour necrosis factor related apoptosis inducing ligand (TRAIL) induces apoptosis in transformed cells and is considered as an agent for cancer therapy. As there is evidence that TRAIL is also essential for apoptosis in animal models of liver injury, we investigated the role of TRAIL in

See end of article for authors' affiliations viral hepatitis and after alcohol consumption.

Methods: Expression of TRAIL was determined by western blot analysis in the liver of patients with chronic hepatitis $\mathrm{C}$ virus (HCV) infection as well as in experimental acute adenoviral hepatitis and after alcohol

Correspondence to: Professor S Kubicka, Department of Gastroenterology, Hepatology, and Endocrinology, Medizinische Hochschule Hannover, Carl Neubergstraße 1, 30625

Hannover, Germany; Kubicka.stefan@ mh-hannover.de

Revised version received 15 February 2005 Accepted for publication 21 February 2005 intake in the liver of mice. To investigate the effect of FasL and TRAIL expression, we used low dose adenoviral gene transfer. Apoptosis and steatosis were assessed by TUNEL and fat red staining, and by caspase assays.

Results: TRAIL was overexpressed in the liver of patients with HCV associated steatosis while acute adenoviral hepatitis resulted in upregulation of TRAIL-DR5. In contrast with FasL, TRAIL expression was harmless to healthy livers. However, in virally infected livers, TRAIL expression induced apoptosis and steatosis whereas expression of FasL only resulted in apoptosis of hepatocytes without steatosis. After alcohol intake, TRAIL expression led to hepatic steatosis, without apoptosis of hepatocytes, indicating that TRAIL mediated apoptosis and steatosis may be independently modulated after viral infection and alcohol intake. In viral hepatitis and after alcohol intake, Ad-TRAIL mediated steatosis can be inhibited by injection of a neutralising TRAIL antibody.

Conclusions: We identified TRAIL as a new mediator of hepatic steatosis in viral hepatitis and after alcohol intake. Consequently, TRAIL mediated hepatotoxicity has to be considered in patients with viral hepatitis and alcoholic liver disease.

$\mathrm{L}$ iver steatosis is a characteristic feature of important liver diseases such as chronic hepatitis C, alcoholic liver disease, and non-alcoholic steatohepatitis (NASH). There is a line of evidence that hepatic steatosis contributes to progression of chronic hepatitis $\mathrm{C}^{1-3}$ and NASH has been proposed as a possible cause of liver cirrhosis and hepatocellular carcinomas. ${ }^{4}$

The pathogenesis of hepatic steatosis is multifactorial and involves insulin resistance, accumulation of intracellular fatty acids, adenosine triphosphate depletion, mitochondrial dysfunction, and oxidative stress. ${ }^{5-8}$ The cytokine tumour necrosis factor $\alpha$ (TNF- $\alpha$ ) is an important mediator of insulin resistance and mediates not only the early stages of fatty liver disease but also the transition to more advanced stages of liver injury. ${ }^{9}$ However, administration of TNF- $\alpha$ to healthy animals promotes proliferation of hepatocytes rather than hepatic steatosis. ${ }^{10}$ Even though TNF- $\alpha$ appears to be a key factor for the development of fatty liver disease in alcohol related liver injury, NASH and chronic hepatitis C, obviously a network of cytokines rather than TNF- $\alpha$ alone is necessary to induce hepatic steatosis.

In addition to TNF- $\alpha$, other members of the TNF family are involved in the pathogenesis of liver diseases. The receptor/ ligand pair Fas (CD95)/FasL (CD95L) has been described as playing an important role in the apoptosis of hepatocytes in viral hepatitis and in alcoholic liver injury. Recently Feldstein et al showed that Fas is strongly overexpressed in hepatocytes in liver specimens from NASH patients, indicating that high Fas activity is involved in apoptosis of hepatocytes in NASH. ${ }^{11}$ While hepatocytes are constitutively susceptible for FasL mediated apoptosis, expression of tumour necrosis factor related apoptosis inducing ligand (TRAIL) does not result in apoptosis of hepatocytes in healthy livers. ${ }^{12-14}$ We recently demonstrated that TRAIL mediated apoptosis of hepatocytes needs to be triggered through viral infection and that overexpression of TRAIL enables the organism to selectively eliminate virally infected hepatocytes. ${ }^{14}$ Recently, Higuchi et al reported that bile acids upregulate TRAIL receptor DR5 expression $^{15-17}$ and Zheng et al demonstrated the essential contribution of TRAIL in Con-A and Listeria induced liver injury, ${ }^{18}$ indicating that TRAIL is also an important mediator of apoptosis in non-viral liver diseases.

TNF receptor 1 (TNFRl), Fas, and the TRAIL receptors 1 (DR4) and 2 (DR5) recruit the key adapter protein FADD to the cell membrane, thereby inducing the caspase cascade. But in contrast with Fas, TNFRl and TRAIL receptors also bind the adapter molecule TRADD, ${ }^{19}{ }^{20}$ which explains the potent activation of nuclear factor $\kappa B$ by TNF- $\alpha$ and TRAIL in contrast with FasL. ${ }^{21}$ The molecular mechanisms in signal transduction by TNF- $\alpha$ and TRAIL are very similar, so it is tempting to speculate that TRAIL may also be involved in the pathogenesis of fatty liver disease.

Consequently, it was the aim of our study to investigate the role of TRAIL in hepatic steatosis. TRAIL expression neither induces apoptosis nor steatosis in healthy livers. However, in virally infected livers and in animals after alcohol intake, TRAIL, but not FasL, expression results in hepatic steatosis. In viral hepatitis, TRAIL mediated steatosis is associated with

Abbreviations: TRAIL, tumour necrosis factor related apoptosis inducing ligand; HCV, hepatitis C virus; TNF- $\alpha$, tumour necrosis factor $\alpha$; TNFR1, TNF receptor 1; NASH, non-alcoholic steatohepatitis 
apoptosis of hepatocytes while expression of TRAIL after alcohol intake induces hepatic steatosis without triggering apoptosis, suggesting two distinct functional pathways for hepatic steatosis and apoptosis in TRAIL signalling.

\section{MATERIAL AND METHODS}

\section{Cell lines and adenovirus preparation}

The human hepatocellular carcinoma cell line Huh7 and the embryonal kidney cell line 293 were obtained from the American Type Culture Collection. Cells were maintained in growth medium (Dulbecco's modified Eagle's medium/ Glutamax (GibcoBRL, Gaithersburg, Maryland, USA), supplemented with $10 \%$ heat inactivated fetal bovine serum (GibcoBRL), 100 units/ml of penicillin, and $100 \mu \mathrm{g}$ of streptomycin) at $37^{\circ} \mathrm{C}$ in $5 \% \mathrm{CO}_{2}$.

Construction and generation of adenoviruses Ad-FasL, Ad-TRAIL, and Ad-GFP have been described previously. ${ }^{14}$ The adenoviral vector Ad5-CMVLacZ was kindly provided by Dr D Brenner (Chapel Hill, USA). Viral infectivity was determined by plaque assays. Endotoxin contaminations were excluded by the LAL-test kit (Chromogenix, Moendal, Sweden) following the protocol provided by the manufacturer. Virus preparations were stored at $-20^{\circ} \mathrm{C}$ in $25 \%$ glycerol, $10 \mathrm{mM}$ Tris/ $\mathrm{HCl}, \mathrm{pH} 7.4$, and $1 \mathrm{mM} \mathrm{MgCl}_{2}$.

\section{Human liver tissues}

Specimens of normal human liver were obtained from two patients who underwent partial hepatectomy because of
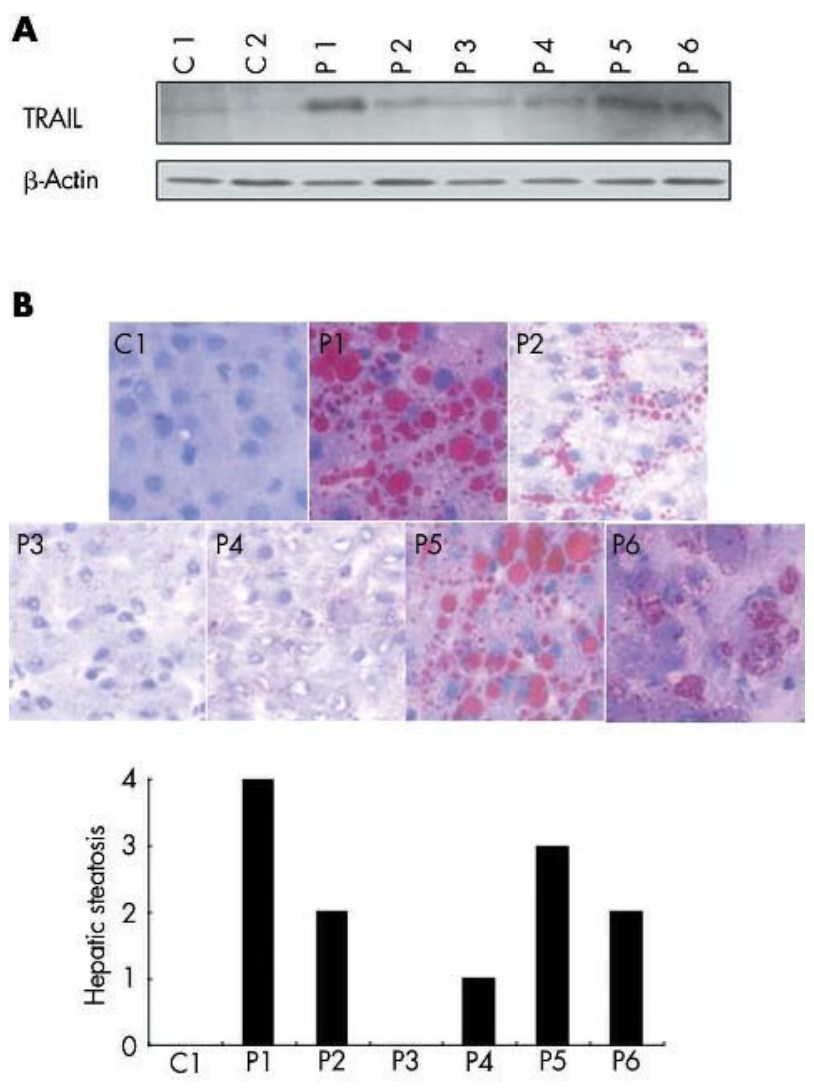

Figure 1 Overexpression of tumour necrosis factor related apoptosis inducing ligand (TRAIL) and steatosis in the livers of patients with chronic hepatitis $C$. (A) Whole cell extracts of normal livers $(\mathrm{Cl}-2)$ and livers from patients with chronic hepatitis $C$ infection $(P 1-6)$ were investigated for protein expression by western blot experiments. TRAIL was overexpressed in the livers of patients with chronic hepatitis $C$ infection. (B) Assessment of hepatic steatosis in the corresponding tissues by fat red staining (magnification 400 $\times$ ). colorectal liver metastases. Specimens of livers from patients with liver cirrhosis due to hepatitis $C$ infection were obtained during liver transplantation at the Medizinische Hochschule Hannover. Anti- hepatitis C virus (HCV) was detected by second or third generation enzyme linked immunosorbent assay (Abbott, Chicago, Illinois, USA), and HCV-RNA was assessed by reverse transcriptase-polymerase chain reaction. Liver specimens were immediately snap frozen in liquid nitrogen after hepatectomy and stored at $-80^{\circ} \mathrm{C}$ until analysis.

\section{Sodium dodecyl sulphate-polyacrylamide gel electrophoresis and western blot analysis}

Protein concentrations of liver extracts were measured by Bio Rad Microassay (Bio Rad, München, Germany). Protein extracts $(10 \mu \mathrm{g})$ were separated on a $10 \%$ sodium dodecyl sulphate-polyacrylamide gel and blotted onto Hybond $\mathrm{N}$ membrane (Millipore, Frankfurt, Germany). The following primary antibodies were used: AF837 against DR5 human and mouse (R\&D, Wiesbaden, Germany), AF630 against DcRl mouse (R\&D), anti-DcR2 against DcR2 mouse (ProSci, Poway, California, USA), C-11 against $\beta$-actin (Santa Cruz, Santa Cruz, California, USA), rabbit polyclonal FasL antibody Ab-1 (Oncogene, Calbiochem, California, USA), and H-257 against TRAIL human and mouse (Santa-Cruz). The antigenantibody complexes were visualised using the ECL detection system, as recommended by the manufacturer (Amersham, Braunschweig, Germany).

\section{Animal experiments}

Pathogen free male Balb/c mice (aged 6-8 weeks) were obtained from the Animal Research Institute of the Medizinische Hochschule Hannover. All experiments were performed in agreement with German legal requirements. Mice were fed a normal standard diet (Altromin, Lage, Germany) given ad libitum. Exposure to ethanol for four days was performed by adding ethanol to the drinking water $(20 \%$ $\mathrm{vol} / \mathrm{vol})$. Metformin was applied orally $(350 \mu \mathrm{g} / \mathrm{kg} /$ day $)$ (Merck, Darmstadt, Germany).

For infection experiments, viruses Ad-LacZ, Ad-GFP, AdFasL, or Ad-TRAIL were prepared, purified, and titred as described previously. ${ }^{14}$ Prior to infection the virus was dialysed twice against a solution containing $10 \mathrm{mM}$ Tris$\mathrm{HCl}, \mathrm{pH}$ 8.0, $1 \mathrm{mM} \mathrm{MgCl}_{2}, 140 \mathrm{mM} \mathrm{NaCl}$ at $4^{\circ} \mathrm{C}$. Infection of mice was carried out by administration of $0.3 \mathrm{ml}$ of virus solution into the tail vein with $1 \times 10^{7}$ to $1 \times 10^{10} \mathrm{pfu} / \mathrm{g}$. At the time points indicated, mice were sacrificed and livers were harvested for preparation of whole cell extracts and cryosections, respectively. To evaluate the efficacy of Ad vectors infecting hepatocytes in vivo, liver specimens of Ad-lacz infected mice were frozen on dry ice and subsequently frozen sections were stained with $\beta$-gal substrate X-gal (5-bromo-4chloro-3-indolyl- $\beta$-D-galactoside) (Sigma, Taufkirchen, Germany).

Monoclonal anti-TRAIL antibody N2B2 (eBioscience, San Diego, California, USA) or an isotype matched control rat IgG antibody was injected into the tail vein ( $125 \mu \mathrm{g}$ or $250 \mu \mathrm{g}$ / mouse) one hour prior to application of Ad-TRAIL.

\section{Fat red staining and TUNEL assay}

Liver tissue of infected mice was embedded in OCT compound (Sakura, Netherlands) and shock frozen in liquid nitrogen. Samples were stored at $-80^{\circ} \mathrm{C}$. Sections $(7 \mu \mathrm{m})$ were prepared and fixed in phosphate buffered saline buffered paraformaldehyde solution (4\%) for 20 minutes at room temperature. For fat red staining, sections were exposed for one hour to fat red (Sigma, Taufkirchen, Germany) counterstained with hemalaun (Merck) for 10 minutes. 
A

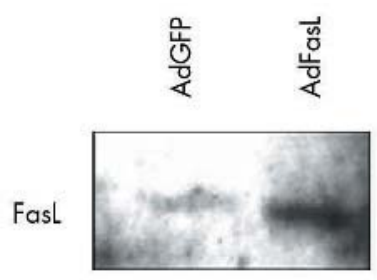

B

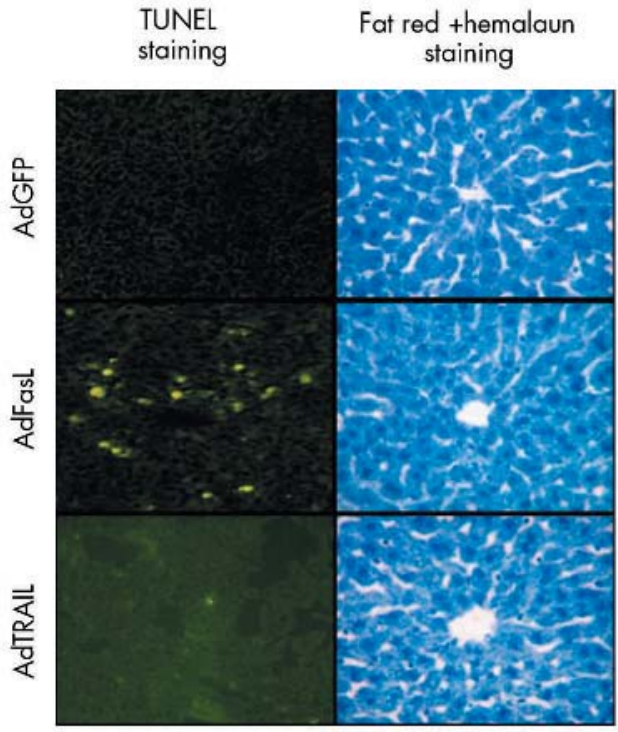

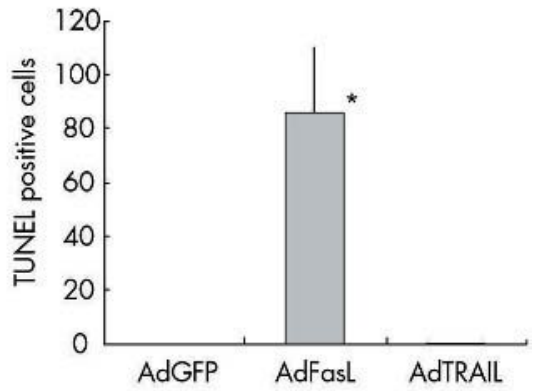

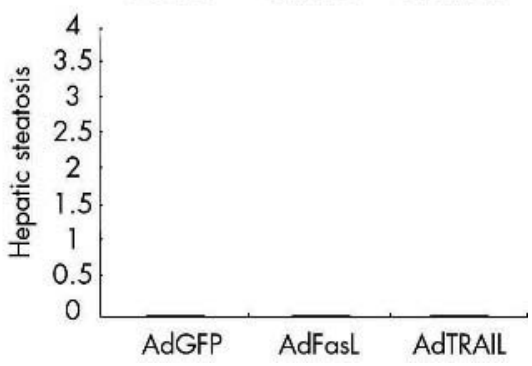

Figure 2 Tumour necrosis factor related apoptosis inducing ligand (TRAIL) induced neither apoptosis nor steatosis in healthy livers. (A) Whole cell extracts of Huh7 cells transduced with AdGFP, AdFasL, or AdTRAll at a multiplicity of infection of 50 were used to investigate adenoviral expression of FasL and TRAIL by western blots. (B) Adenoviral vectors AdGFP, AdFasL, and AdTRAIL ( $\left.1 \times 10^{7} \mathrm{pfu} / \mathrm{g}\right)$ were administered into the tail vein of Balb/c mice. Twenty four hours later mice were killed and analysed for apoptosis by TUNEL assay (magnification 200 $\times$ ) and steatosis by fat red staining (magnification $400 \times$ ). AdFasL resulted in significant $\left(^{*}\right)$ apoptosis. Figure shows representative data from four independent experiments.

For TUNEL assays we used the In Situ Cell Death Detection Kit, Fluorescein (Boehringer, Mannheim, Germany). After incubation with proteinase $\mathrm{K}$ and Triton X-100, sections were stained as described in the protocol provided by the manufacturer. The number of TUNEL positive cells was assessed for each liver by counting TUNEL positive cells in three sections. For each section 10 fields (magnification $\times 400$ ) were examined. The results were processed using the Student's $t$ test, with $\mathrm{p}<0.05$ accepted as denoting statistical significance.

\section{Assessment of hepatic steatosis}

Hepatic steatosis was evaluated using a scale of $0-4$. A score of 0 indicated no vesicular fat was present; scores of 1, 2, 3, and 4 corresponded to the following number of cells (expressed as a percentage of the total number of cells) that contained vesicular fat: $\leqslant 25,25-50,50-75$, and $75-100$. For each liver, three sections and for each section, 10 fields (magnification $\times 200$ ) were examined. The results were processed using the Student's $t$ test, with $\mathrm{p}<0.05$ accepted as denoting statistical significance.

\section{Assessment of caspase 8 activity in liver tissue}

For determination of caspase 8 activity in the mouse liver, freshly harvested organs were subjected to a buffer containing $25 \mathrm{mM}$ HEPES, $5 \mathrm{mM} \mathrm{MgCl}_{2}, 5 \mathrm{mM}$ EDTA, $2 \mathrm{mM}$ dithiothreitol, $0.1 \%$ CHAPS, $0.5 \mathrm{mM}$ Pefabloc, $0.1 \mathrm{mg} / \mathrm{ml}$ leupeptin, and $0.1 \mathrm{mg} / \mathrm{ml}$ pepstatin in a $\mathrm{w} / \mathrm{v}$ ratio of $1: 3$. For preparation of whole cell extracts, tissue was homogenised on ice and subsequently centrifuged at $12000 \mathrm{~g}$ for
10 minutes $\left(4^{\circ} \mathrm{C}\right)$. Total protein $(100 \mu \mathrm{g})$ from the supernatant was used to measure caspase 8 activity by the ApoAlert Caspase Fluorescent Assay kit (BD Bioscience, Heidelberg, Germany). The specificity of the results was controlled by adding a caspase 8 inhibitor (C 8 inhi.), as suggested by the manufacturer.

Three livers from three independent experiments were used in each group. The results were processed using the Student's $t$ test to compare differences between groups. A p value of $<0.05$ was considered statistically significant.

\section{RESULTS}

\section{Expression of TRAIL in virally infected livers induces} hepatic steatosis and apoptosis

Liver steatosis is characteristic of HCV infection. ${ }^{22} 23$ To investigate whether TRAIL is upregulated in liver with hepatitis C associated hepatic steatosis, we performed western blot experiments in liver tissues from patients with chronic hepatitis C. Compared with normal liver, TRAIL was overexpressed in the liver of patients with hepatitis C. However, the quantity of fat accumulation in hepatocytes did not tightly correlate with hepatic TRAIL expression (fig l).

To determine whether expression of TRAIL resulted in hepatic steatosis, we used adenoviral vectors expressing FasL or TRAIL (fig 2A). There was no evidence of fatty liver disease or apoptosis of hepatocytes after infection of healthy livers with low amounts of Ad-TRAIL, confirming our previous observation that TRAIL, in contrast with FasL, was not harmful to healthy livers (fig 2B). 
A

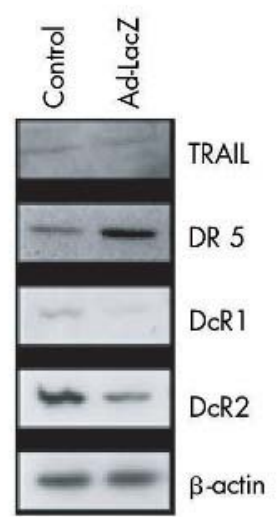

B

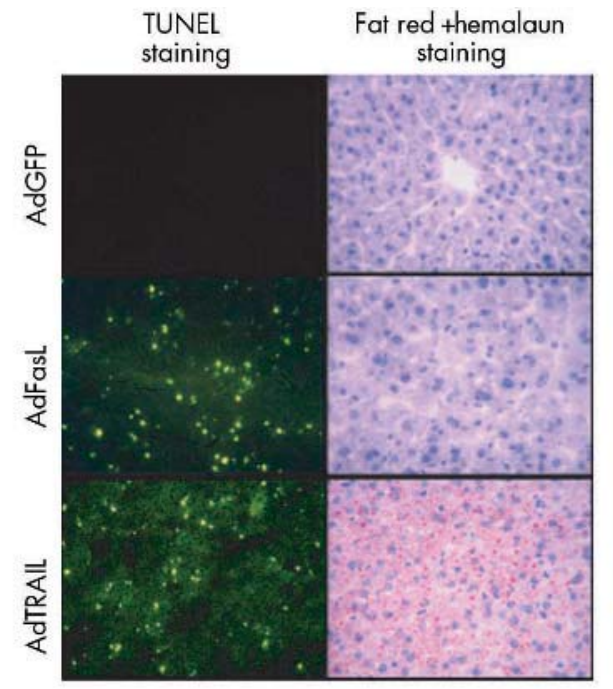

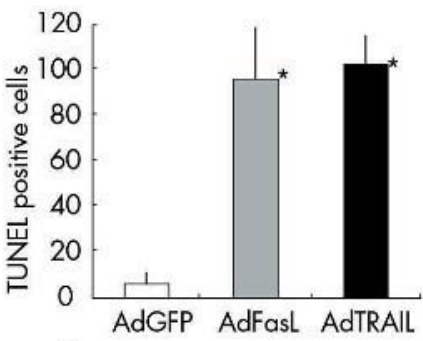

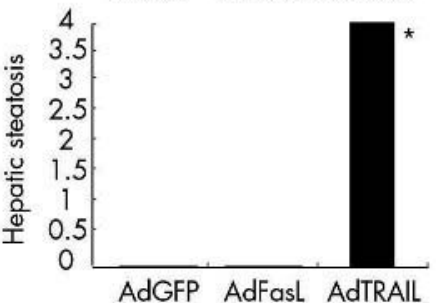

C

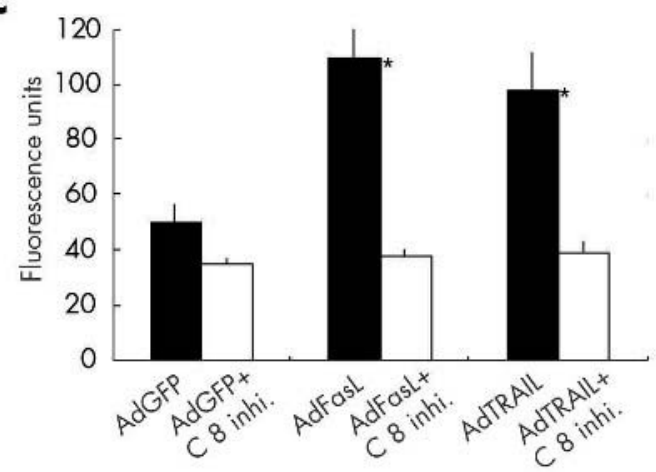

D

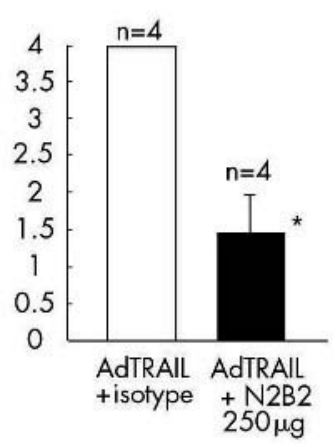

Figure 3 Viral hepatitis sensitised for tumour necrosis factor related apoptosis inducing ligand (TRAIL) mediated apoptosis and steatosis. (A) Viral hepatitis was induced by intravenous application of $1 \times 10^{10} \mathrm{pfu} / \mathrm{g}$ of AdlacZ into Balb/c mice. After 40 hours whole cell extracts of the livers were isolated and investigated for protein expression of TRAIL, DR5, DcR1, DcR2, and $\beta$-actin by western blot experiments. (B) Adenoviral vectors AdGFP, AdFasL, and Ad-TRAIL $\left(1 \times 10^{7} \mathrm{pfu} / \mathrm{g}\right)$ were administered into the tail vein of Balb/c mice 24 hours after pretreatment with $5 \times 10^{7} \mathrm{pfu} / \mathrm{g}$ of AdlacZ. Twenty four hours after the last injection, apoptosis of hepatocytes was analysed by TUNEL assay (magnification $200 \times$ ) and steatosis by fat red staining (magnification 200x). Figure shows representative data of four independent experiments. (C) Adenoviral vectors AdGFP, AdFasL, and AdTRAIL $\left(1 \times 10^{7} \mathrm{pfu} / \mathrm{g}\right)$ were administered into the tail vein of Ballb/c mice 24 hours after pretreatment with $5 \times 10^{7} \mathrm{pfu} / \mathrm{g}$ of AdlacZ. Twenty four hours after the last injection, livers were harvested for caspase 8 assays. FasL and TRAlL significantly (*) induced caspase 8 activity. C 8 inhi., caspase 8 inhibitor. (D) In animals with adenoviral hepatitis, one hour prior to AdTRAll application, anti-TRAll antibody N2B2 (250 $\mu \mathrm{g} /$ mouse) or isotype control antibody $(250 \mu \mathrm{g} / \mathrm{mouse})$ was injected into the tail vein. Hepatic steatosis was assessed by fat red staining. Administration of TRAll neutralising antibody significantly ${ }^{*}$ ) inhibited TRAll mediated hepatic steatosis. Figure shows representative data of four independent experiments (magnification 600×).

It has been hypothesised that the interplay of different cytokines rather than one particular ligand may be necessary for the development of fatty liver disease. ${ }^{9}$ Consequently, we explored whether viral infection may be a predisposing condition for TRAIL mediated hepatic steatosis. Prior infection of mice with high doses of adenoviruses (Ad-lacZ) caused downregulation of the TRAIL decoy receptor DcR2 and upregulation of TRAIL receptor DR5 expression, and sensitised hepatocytes to TRAIL mediated steatosis and apoptosis, as shown in fig $3 \mathrm{~A}$ and $3 \mathrm{~B}$. In contrast with TRAIL mediated apoptosis, FasL mediated apoptosis was not associated with hepatic steatosis, although both Ad-FasL and Ad-TRAIL induced caspase 8 activity in the liver (fig 3B, 3C).

To confirm that hepatic steatosis in our animal model was specifically induced by TRAIL, we inhibited TRAIL with the anti-TRAIL antibody N2B2. Compared with an isotype control antibody, systemic application of N2B2 significantly prevented TRAIL mediated steatosis in animals with viral hepatitis, as shown in fig 3D.

\section{Expression of TRAIL after alcohol intake results in hepatic steatosis without apoptosis}

TNF- $\alpha$ plays an important role in alcoholic fatty liver disease. ${ }^{24}$ Consequently, we investigated whether expression of TRAIL after alcohol intake would result in hepatic steatosis. Feeding of mice with $20 \%$ alcohol for four days did not lead to significant regulation of TRAIL or TRAIL receptors in the liver (fig 4A). Nevertheless, alcohol intake also sensitised the liver to TRAIL mediated steatosis, as shown in fig 4B. However, in contrast with viral hepatitis, expression of TRAIL in animals after alcohol intake resulted only in accumulation of fat within the hepatocytes, but not in apoptosis of hepatocytes, suggesting distinct functional pathways for TRAIL regarding regulation of apoptosis and steatosis (fig 4B). To confirm that TRAIL mediated steatosis is not dependent on apoptosis under these circumstances, we assessed caspase 8 activity in the livers of the animals. In contrast with adenoviral hepatitis, administration of AdTRAIL did not enhance caspase 8 activity in the liver, 

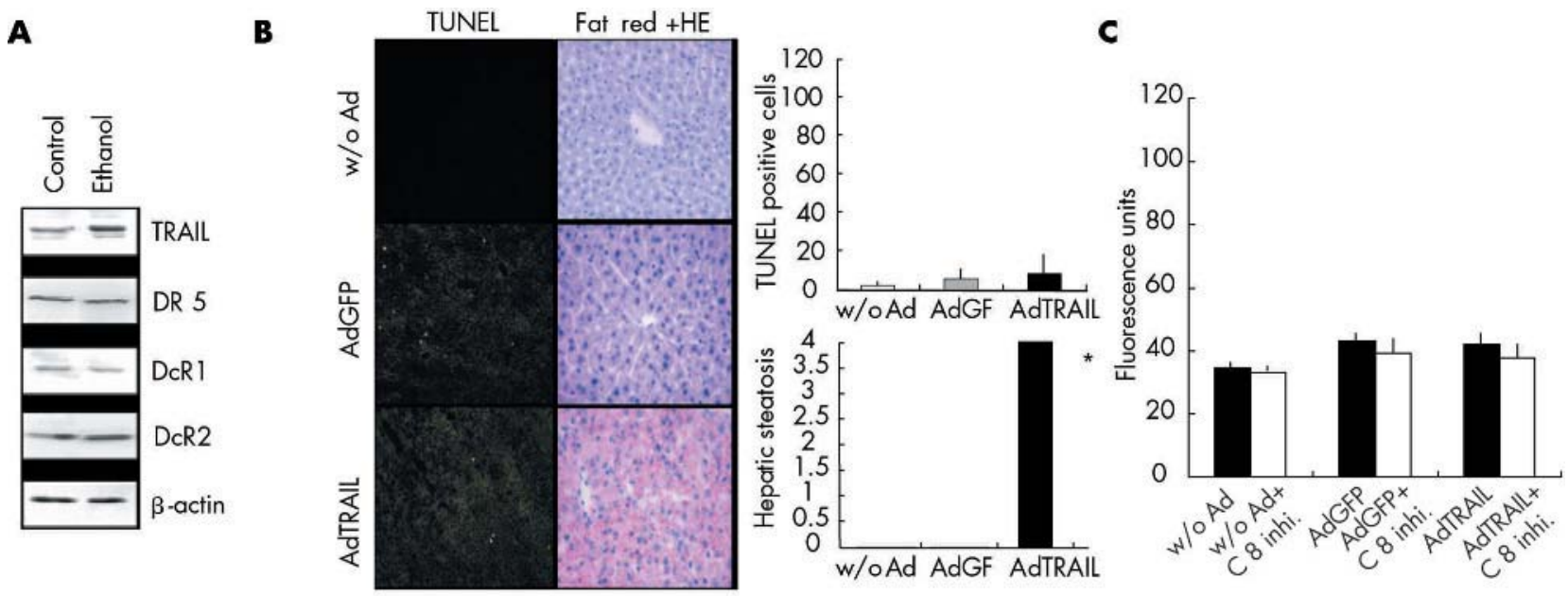

D

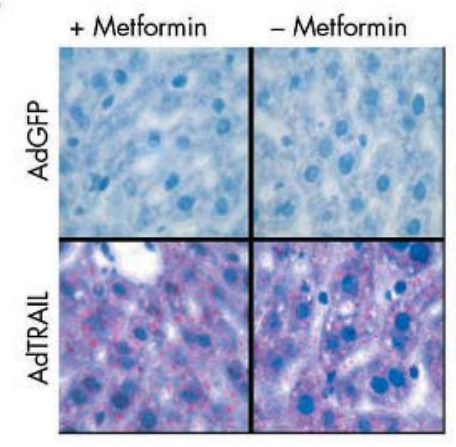

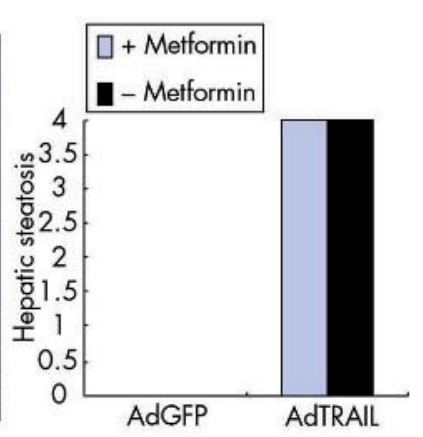

E

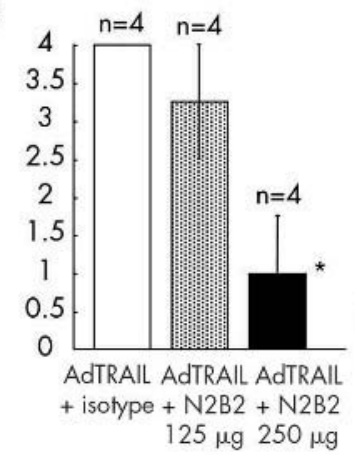

Figure 4 Alcohol intake sensitised for tumour necrosis factor related apoptosis inducing ligand (TRAIL) mediated hepatic steatosis but not apoptosis. (A) Balb/c mice were fed with $20 \%$ ethanol for four days. Whole cell extracts were isolated from mouse livers and were investigated for protein expression by western blot experiments. (B) Balb/c mice were fed $20 \%$ ethanol. After four days, AdGFP and AdTRAlL $\left(1 \times 10^{7} \mathrm{pfu} / \mathrm{g}\right)$ were injected into the tail vein. Twenty four hours later, animals were killed and the livers were analysed for apoptosis and steatosis by TUNEL assay (magnification $200 \times$ ) and fat red staining (magnification 400x). Alcohol feeding significantly (*) sensitised hepatocytes to TRAIL mediated steatosis but not to TRAIL mediated apoptosis. Figure shows representative data of four independent experiments. (C) Balb/c mice were fed $20 \%$ ethanol. After four days, AdGFP and AdTRAIL $\left(1 \times 10^{7} \mathrm{pfu} / \mathrm{g}\right)$ were injected into the tail vein. Twenty four hours after AdGFP and AdTRAIL, livers were harvested for caspase 8 assays. Ad-GFP and Ad-TRAlL did not enhance caspase 8 activity compared with animals without adenoviral treatment (w/o Ad). C 8 inhi., caspase 8 inhibitor. (D) Animals were fed for four days $20 \%$ ethanol and one group also received $350 \mu \mathrm{g} / \mathrm{kg} / \mathrm{day}$ metformin. Fat red staining of livers was performed 24 hours after injection of AdTRAIL and Ad-GFP $\left(1 \times 10^{7} \mathrm{pfu} / \mathrm{g}\right)$ (magnification $400 \times$ ). Figure shows representative data of four independent experiments. (E) After alcohol intake, animals received AdTRAlL $\left(1 \times 10^{7} \mathrm{pfu} / \mathrm{g}\right)$. One hour prior to AdTRAlL application, anti-TRAlL antibody N2B2 (125 $\mu \mathrm{g}$ or $250 \mu \mathrm{g} / \mathrm{mouse}$ ) or isotype control antibody ( $250 \mu \mathrm{g} / \mathrm{mouse}$ ) was injected into the tail vein. Hepatic steatosis was assessed by fat red staining. Administration of TRAll neutralising antibody significantly $\left(^{*}\right)$ inhibited TRAlL mediated hepatic steatosis at a dose of $250 \mu \mathrm{g} /$ mouse. Figure shows representative data of four independent experiments (magnification $600 \times$ ).

indicating that TRAIL mediated steatosis is independent of caspase 8 activity (fig 4C).

TNF- $\alpha$ induces hepatic steatosis by mediating insulin resistance through its effects on several important sites of insulin action..$^{25}$ As it has been shown that metformin improves insulin resistance and fatty liver disease in ob/ob mice, ${ }^{27}$ we investigated whether metformin is capable of preventing hepatic steatosis in animals after alcohol intake and after administration of Ad-TRAIL. As shown in fig 4D, metformin did not protect the liver against TRAIL mediated steatosis. According to the experiments in viral hepatitis, application of anti-TRAIL antibodies significantly prevented TRAIL mediated steatosis in animals after alcohol intake, as shown in fig 4E.

\section{DISCUSSION}

TRAIL has received particular attention because early reports suggest that it induces apoptosis in a variety of cancer cells with little or no effect on normal cells. As a consequence, recombinant soluble TRAIL was believed to be safe for use as a cancer therapy agent without damaging intact tissues. Preclinical studies in mice ${ }^{12}$ and non-human primates ${ }^{13}$ have been very promising but some investigators described TRAIL mediated toxicity in normal human cells, such as keratinocytes ${ }^{28}$ hepatocytes, ${ }^{29}$ and brain cells, ${ }^{30}$ raising the concern that TRAIL might cause unexpected toxicity in humans. Actually, it became apparent that different recombinant TRAIL preparations exhibit significant biological differences and recent results indicate that administration of TRAIL lacking exogenous sequence tags or leucine zipper domains is effective in tumour therapy but is unlikely to cause toxicity to healthy human tissues. ${ }^{31}$

The physiological role of TRAIL expression is largely unknown. The main function of TRAIL appears to be the negative regulation of the immune system to prevent autoimmunity $^{32}$ but some investigators propose that TRAIL may also serve as an important effector molecule on activated $\mathrm{T}$ and B lymphocytes, natural killer cells, monocytes, and dendritic cells. ${ }^{33-36}$ We recently showed that TRAIL and TRAIL receptor DR5 are involved in apoptosis of hepatocytes in viral 
hepatitis. ${ }^{14}$ In contrast with FasL, TRAIL mediated apoptosis of hepatocytes in vivo needs triggering through viral infection, confirming the hypothesis that TRAIL is an essential tool of an innate defence mechanism against viruses.

In this report we demonstrated that hepatic expression of TRAIL, in contrast with FasL, induced fatty liver disease in viral hepatitis and after alcohol intake. Expression of TRAIL did not induce steatosis in untreated animals, indicating a precondition of an environment in which other cytokines sensitises hepatocytes for TRAIL mediated steatosis. The molecular basis for this sensitisation remains uncertain but it may resemble, at least in part, the mechanisms involved in the susceptibility of the liver to TNF- $\alpha$ mediated steatosis.

Under normal conditions, hepatocytes are resistant to TNF- $\alpha$ induced steatosis ${ }^{10}$ but several cytokines released by macrophages such as interferon $\gamma$ and interleukin 12 are known to promote TNF- $\alpha$ mediated steatohepatitis. ${ }^{37} 38$ As type I or II interferons strongly induce TRAIL expression on several effector cells of the immune system, ${ }^{35} 36{ }^{39}$ TRAIL may also enhance TNF- $\alpha$ induced steatosis during viral hepatitis.

In our study, TRAIL mediated apoptosis was associated with hepatic steatosis only in viral hepatitis while expression of TRAIL induced neither apoptosis nor caspase 8 activity in animals after alcohol intake. These results suggest that TRAIL mediated apoptosis and steatosis may be independently modulated by additional cytokines released during viral infection and after alcohol intake. It has been shown that CD40 engagement triggers apoptosis of human hepatocytes and may amplify Fas dependent hepatocyte apoptosis in inflammatory liver diseases. ${ }^{40}$ In addition, CD40 ligation can induce functional expression of Fas ligand, TRAIL, and TNF- $\alpha$ in cancer cells, ${ }^{41}$ indicating an important role for CD40 as a modifying signal in receptor mediated apoptosis. It appears likely that CD40 engagement is also involved in our animal models and the contribution of CD40 to TRAIL mediated apoptosis and steatosis should be investigated in further studies.

Our results demonstrate that TRAIL is a new mediator of hepatic steatosis in viral hepatitis and after alcohol intake. As a consequence of our study, hepatotoxicity has to be considered in clinical trials with TRAIL in patients with viral hepatitis, alcoholic liver disease, or other liver diseases that may activate TRAIL sensitivity in hepatocytes. In this regard it is important to note that even a short duration of alcohol consumption was sufficient to increase the susceptibility of hepatocytes to TRAIL mediated steatosis in our experiments. However, in both of our animal models of TRAIL mediated steatosis, application of neutralising anti-TRAIL antibodies was capable of inhibiting liver steatosis. Thus our results also suggest that, in addition to TNF- $\alpha$, TRAIL may be a new attractive therapeutic target for inhibition of hepatic steatosis.

\section{ACKNOWLEDGEMENTS}

Research was supported by grants of the Deutsche Forschungsgemeinschaft (KU 1213/3-1) and the Deutsche Krebshilfe (10-2078-Ku2).

\section{Authors' affiliations}

B Mundt*, T Wirth", L Zender, M Waltemathe, C Trautwein, M P Manns, F Kühnel, S Kubicka, Department of Gastroenterology, Hepatology, and Endocrinology, Medical School Hannover, Germany

*B Mundt and T Wirth contributed equally to this work and should be considered as first authors

Conflict of interest: None declared.

\section{REFERENCES}

1 Adinolfi LE, Gambardella M, Andreana A, et al. Steatosis accelerates the progression of liver damage of chronic hepatitis $C$ patients and correlates with specific HCV genotype and visceral obesity. Hepatology 2001;33:1358-64.

2 Serfaty L, Poujol-Robert A, Carbonell N, et al. Effect of the interaction between steatosis and alcohol intake on liver fibrosis progression in chronic hepatitis $\mathrm{C}$. Am J Gastroenterol 2002;97:1807-12.

3 Castera L, Hezode C, Roudot-Thoraval F, et al. Worsening of steatosis is an independent factor of fibrosis progression in untreated patients with chronic hepatitis C and paired liver biopsies. Gut 2003;52:288-92.

4 Bugianesi E, Leone N, Vanni E, et al. Expanding the natural history of nonalcoholic steatohepatitis: from cryptogenic cirrhosis to hepatocellular carcinoma. Gastroenterology 2002;123:134-40.

5 Day C, Saksena S. Non-alcoholic steatohepatitis: Definitions and pathogenesis. J Gastroenterol Hepatol 2002;17(suppl 3):S377-84.

6 Harrison SA, Kadakia S, Lang KA, et al. Nonalcoholic steatohepatitis: what we know in the new millennium. Am J Gastroenterol 2002;97:2714-24.

7 Mulhall BP, Ong JP, Younossi ZM. Non-alcoholic fatty liver disease: an overview. J Gastroenterol Hepatol 2002;17:1136-43.

8 Pessayre D, Mansouri A, Fromenty B. Nonalcoholic steatosis and steatohepatitis. V. Mitochondrial dysfunction in steatohepatitis. Am J Physiol Gastrointest Liver Physiol 2002;282:G193-9.

9 Tilg H, Diehl AM. Cytokines in alcoholic and nonalcoholic steatohepatitis. N Engl J Med 2000;343:1467-76.

10 Feingold KR, Soued M, Grunfeld C. Tumor necrosis factor stimulates DNA synthesis in the liver of intact rats. Biochem Biophys Res Commun 1988; 153:576-82.

11 Feldstein AE, Canbay A, Angulo P, et al. Hepatocyte apoptosis and fas expression are prominent features of human nonalcoholic steatohepatitis. Gastroenterology 2003;125:437-43.

12 Walczak H, Miller RE, Ariail K, et al. Tumoricidal activity of tumor necrosis factor-related apoptosis-inducing ligand in vivo. Nat Med 1999;5:157-63.

13 Ashkenazi A, Pai RC, Fong S, et al. Safety and antitumor activity of recombinant soluble Apo2 ligand. J Clin Invest 1999;104:155-62.

14 Mundt B, Kuhnel F, Zender L, et al. Involvement of TRAIL and its receptors in viral hepatitis. FASEB J 2003;17:94-6.

15 Higuchi $H$, Bronk SF, Taniai $M$, et al. Cholestasis increases tumor necrosis factor-related apoptotis-inducing ligand (TRAIL)-R2/DR5 expression and sensitizes the liver to TRAlL-mediated cytotoxicity. J Pharmacol Exp Ther 2002;303:461-7

16 Higuchi H, Yoon JH, Grambihler A, et al. Bile acids stimulate cFLIP phosphorylation enhancing TRAlL-mediated apoptosis. J Biol Chem 2003;278:454-61

17 Higuchi H, Grambihler A, Canbay A, et al. Bile acids up-regulate death receptor 5/TRAlL-receptor 2 expression via a c-Jun $\mathrm{N}$-terminal kinasedependent pathway involving Sp1. J Biol Chem 2004;279:51-60.

18 Zheng SJ, Wang P, Tsabary G, et al. Critical roles of TRAIL in hepatic cell death and hepatic inflammation. J Clin Invest 2004;1 13:58-64.

19 Chaudhary PM, Eby M, Jasmin A, et al. Death receptor 5, a new member of the TNFR family, and DR4 induce FADD-dependent apoptosis and activate the NF-kappaB pathway. Immunity 1997;7:821-30.

20 Schneider $\mathbf{P}$, Thome M, Burns K, et al. TRAlL receptors 1 (DR4) and 2 (DR5) signal FADD-dependent apoptosis and activate NF-kappaB. Immunity 1997;7:831-6.

21 Karin M, Lin A. NF-kappaB at the crossroads of life and death. Nat Immunol 2002;3:221-7.

22 Kumar D, Farrell GC, Fung C, et al. Hepatitis C virus genotype 3 is cytopathic to hepatocytes: Reversal of hepatic steatosis after sustained therapeutic response. Hepatology 2002;36:1266-72.

23 Perlemuter G, Sabile A, Letteron $P$, et al. Hepatitis $C$ virus core protein inhibits microsomal triglyceride transfer protein activity and very low density lipoprotein secretion: a model of viral-related steatosis. FASEB J 2002; 16:185-94

24 Yin $M$, Wheeler MD, Kono $H$, et al. Essential role of tumor necrosis factor alpha in alcohol-induced liver injury in mice. Gastroenterology 1999; 117:942-52.

25 Hotamisligil GS, Peraldi P, Budavari A, et al. IRS-1-mediated inhibition of insulin receptor tyrosine kinase activity in TNF-alpha- and obesity-induced insulin resistance. Science 1996:271:665-8.

26 Uysal KT, Wiesbrock SM, Marino MW, et al. Protection from obesity-induced insulin resistance in mice lacking TNF-alpha function. Nature 1997;389:610-14.

27 Lin HZ, Yang SQ, Chuckaree C, et al. Metformin reverses fatty liver disease in obese, leptin-deficient mice. Nat Med 2000;6:998-1003.

28 Leverkus M, Neumann M, Mengling T, et al. Regulation of tumor necrosis factor-related apoptosis-inducing ligand sensitivity in primary and transformed human keratinocytes. Cancer Res 2000;60:553-9.

29 Jo M, Kim TH, Seol DW, et al. Apoptosis induced in normal human hepatocytes by tumor necrosis factor-related apoptosis-inducing ligand. Nat Med 2000;6:564-7

30 Nitsch R, Bechmann I, Deisz RA, et al. Human brain-cell death induced by tumour-necrosis-factor-related apoptosis-inducing ligand (TRAIL). Lancet 2000;356:827-8

31 Lawrence D, Shahrokh Z, Marsters S, et al. Differential hepatocyte toxicity of recombinant Apo2L/TRAll versions. Nat Med 2001;7:383-5.

32 Lamhamedi-Cherradi SE, Zheng SJ, Maguschak KA, et al. Defective thymocyte apoptosis and accelerated autoimmune diseases in TRAILI-/-) mice. Nat Immunol 2003;4:255-60.

33 Mariani SM, Krammer PH. Surface expression of TRAIL/Apo-2 ligand in activated mouse T and B cells. Eur J Immunol 1998;28:1492-8. 
34 Zamai L, Ahmad M, Bennett IM et al. Natural killer (NK) cell-mediated cytotoxicity: differential use of TRAIL and Fas ligand by immature and mature primary human NK cells. J Exp Med 1998;188 2375-80.

35 Fanger NA, Maliszewski CR, Schooley K, et al. Human dendritic cells mediate cellular apoptosis via tumor necrosis factor-related apoptosis-inducing ligand (TRAIL). J Exp Med 1999;190:1 155-64.

36 Griffith TS, Wiley SR, Kubin MZ, et al. Monocyte-mediated tumoricidal activity via the tumor necrosis factor-related cytokine, TRAIL. J Exp Med $1999 \cdot 189 \cdot 1343-54$

37 Yang SQ, Lin HZ, Lane MD, et al. Obesity increases sensitivity to endotoxin liver injury: implications for the pathogenesis of steatohepatitis. Proc Natl Acad Sci U S A 1997;94:2557-62.
38 Chikano S, Sawada K, Shimoyama T, et al. IL-18 and IL-12 induce intestinal inflammation and fatty liver in mice in an IFN-gamma dependent manner. Gut 2000;47:779-86.

39 Takeda K, Smyth MJ, Cretney E, et al. Critical role for tumor necrosis factorrelated apoptosis-inducing ligand in immune surveillance against tumor development. J Exp Med 2002;195:161-9.

40 Afford SC, Randhawa S, Eliopoulos AG, et al. CD40 activation induces apoptosis in cultured human hepatocytes via induction of cell surface fas ligand expression and amplifies fas-mediated hepatocyte death during allograft rejection. J Exp Med 1999;189:441-6.

41 Eliopoulos AG, Davies C, Knox PG, et al. CD40 induces apoptosis in carcinoma cells through activation of cytotoxic ligands of the tumor necrosis factor superfamily. Mol Cell Biol 2000;20:5503-15.

\section{EDITOR'S QUIZ: GI SNAPSHOT}

\section{A calcified and cystic peripancreatic mass}

\section{Clinical presentation}

A 33 year old woman with no previous medical history presented with acute epigastric pain and nausea. Her physical examination was essentially unremarkable. Chest $x$ ray and urgent blood investigations were normal, including serum amylase, lipase, and hepatic enzymes. Abdominal ultrasound was performed and calcified masses was found anterior to the pancreas. An abdominal computed tomography scan was requested (fig 1). After surgical resection, histopathological examination was performed (fig 2).

\section{Question}

What is the diagnosis?

See page 1629 for answer

This case is submitted by:

S Bageacu, D Kaczmarek Department of General Surgery, University Hospital of Saint-Etienne, Hôpital Nord, Saint-Etienne, France

Correspondence to: Dr S Bageacu, Department of General Surgery, University Hospital of Saint-Etienne, Hôpital Nord 42055 Saint-Etienne Cedex 2, France; serban.bageacu@chu-st-etienne.fr

doi: $10.1136 /$ gut.2005.068502
Robin Spiller, Editor

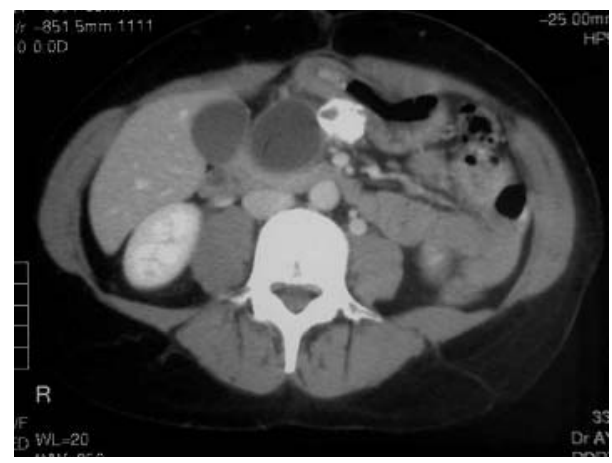

Figure 1 Computed tomography scan of the abdomen showing a cystic calcified mass.

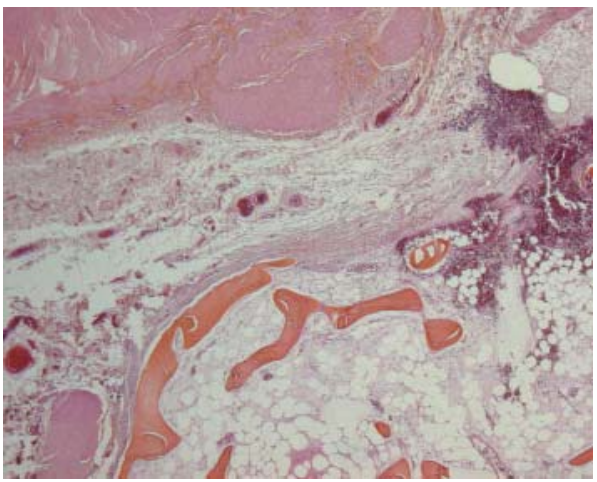

Figure 2 Histopathological specimen showing the muscular layer in the right upper side and bone tissue in the left lower side (orange). 